科 学 通 报

\title{
几种氨基酸对铜、金的淋滤作用的实验研究 *
}

\author{
刘金钟 傅家谟 卢家烂 \\ (中国科学院广州地质新技术研究所，有机地球化学国家重点开放实验室，广州 510640)
}

\section{关链词地球化学、䔬基酸、铜、金、模拟实验}

在一些以沉积岩系为矿源层的层控矿床的成矿过程中,生物遗体降解产生的氨基酸可能 对于成矿物质的活化迁移方面起了重要的作用 ${ }^{[1,2]}$. 但目前研究者的注意力多集中于脂肪 酸、腐殖酸对金属的络合作用 ${ }^{[3,4]}$, 致使关于氨基酸对金属的络合、淋滤作用的可用的数据很 少. 为此本文用模拟实验方法研究了几种含氨基酸溶液对岩石中铜、金的淋滤络合作用并讨 论了其地球化学意义.

\section{1 实验方法及结果}

\section{1 实验 1 - - 含氨基酸水溶液对铜的淋滤络合作用}

实验中所用有机质种类参考前人对地质体中存在的天然有机质的分析结果 ${ }^{[?]}$ ，但考虑到 实验不可能达到地质过程的漫长时间,故实验中所

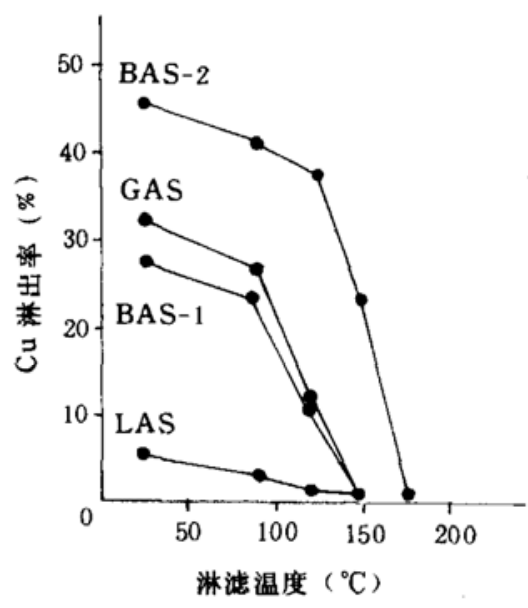

图 1 含氨基酸水溶液对铜的淋渍络合作用 图中各曲线的溶液成分如下：GAS: $0.004 \mathrm{~mol} / \mathrm{L}$ 甘氨酸 (氨基乙酸); BAS-1: $0.004 \mathrm{~mol} / \mathrm{L}$ 丙祌酸; BAS-2: $0.0056 \mathrm{~mol} / \mathrm{L}$ 丙氨酸; LAS: $0.002 \mathrm{~mol} / \mathrm{L}$ (即: 0.004 当量浓度) 赖氨酸 用有机质的浓度略高于此类有机质的天然浓度, 以 提高反应速率．铜的淋滤岩石为人工配制, 方法是 用桂西北板纳组粉砂岩粉碎至 200 目, 加人适量 $\mathrm{CuCl}_{2}$ 水溶液, 充分混合后在 $200^{\circ} \mathrm{C}$ 下烘烤 $24 \mathrm{~h}$, 即 为被淋滤样品, 其中含 $\mathrm{Cu}$ (氧化铜 $) 667 \mathrm{ppm}$. 取 $1 \mathrm{~g}$ 或 $2 \mathrm{~g}$ 岩样加人 $10 \mathrm{ml}$ 或 $20 \mathrm{ml}$ 含氨基酸水溶液,分别 封人玻管 $\left(25-125^{\circ} \mathrm{C}\right)$ 或高压釜 $\left(150-200^{\circ} \mathrm{C}\right)$ 在不同温度下反应一段时间. 反应结束后分离溶 液, 经高氯酸氧化去除有机质后测定溶液中的铜 浓度. 实验结果见图 1 、表 1 .

\section{2 实验 2 一虫基乙酸对含金岩石中金的淋漟 作用}

被淋滤的岩石采自广西凤山县金牙微细浸染型 金矿床 (含金粉砂岩) ${ }^{[6}$, 主要造岩矿物为石英、长 石、粘土矿物及碳酸盐等，矿样中金含量为 $5 \mathrm{ppm}$, $90 \%$ 以上的金赋存在黄铁矿、毒砂等硫化物中．岩

1993-11-17 收稿, 1994-03-21 收修改稿.

*国家自然科学基金和国家博士后科研基金资助项目. 
表 1 含氨基酸水溶液对 $\mathrm{Cu}$ 的淋滤作用 ${ }^{\mathrm{a}}$

\begin{tabular}{|c|c|c|c|c|c|c|c|c|}
\hline $\begin{array}{l}\text { 温度 } \\
\left({ }^{\circ} \mathrm{C}\right)\end{array}$ & $\begin{array}{c}\text { 反应 } \\
\text { 时间 (d) }\end{array}$ & $\begin{array}{l}\text { 溶液 } \\
\text { 成分 }\end{array}$ & $\begin{array}{c}\text { 溶液中 } \\
\mathrm{Cu}(\mathrm{ppm})\end{array}$ & $\begin{array}{c}\text { 反应前 } \\
\mathrm{pH}\end{array}$ & $\begin{array}{l}\text { 反应前 } \\
E h(V)\end{array}$ & $\begin{array}{c}\text { 反应后 } \\
\mathrm{pH}\end{array}$ & $\begin{array}{l}\text { 反应后 } \\
\operatorname{Eh}(\mathrm{V})\end{array}$ & $\begin{array}{c}\text { 淋出率 } \\
(\%)\end{array}$ \\
\hline 25 & 4 & GAS & 43.8 & 6.60 & 0.165 & 6.75 & 0.109 & 32.8 \\
\hline 90 & 4 & GAS & 36.0 & $6.60^{\circ}$ & 0.165 & 6.70 & 0.104 & 27.0 \\
\hline 120 & 4 & GAS & 16.3 & 6.60 & 0.165 & 6.50 & 0.088 & 12.2 \\
\hline 150 & 4 & GAS & 0.30 & 6.60 & 0.165 & 6.28 & 0.092 & 0.22 \\
\hline 25 & 4 & BAS-1 & 36.9 & 6.20 & 0.204 & 6.81 & 0.107 & 27.7 \\
\hline 90 & 4 & BAS-1 & 31.5 & 6.20 & 0.204 & 6.58 & 0.106 & 23.6 \\
\hline 120 & 4 & BAS-1 & 15.6 & 6.20 & 0.204 & 6.28 & 0.092 & 11.7 \\
\hline 150 & 4 & BAS-1 & 0.44 & 6.20 & 0.204 & 6.18 & 0.077 & 0.33 \\
\hline 25 & 20 & BAS-2 & 15.4 & & \multirow{6}{*}{ 末 } & \multirow{6}{*}{ 测 } & & 46.2 \\
\hline 90 & 7 & BAS-2 & 13.9 & & & & & 41.6 \\
\hline 125 & 7 & BAS-2 & 12.8 & & & & & 38.4 \\
\hline 150 & 7 & BAS-2 & 8.3 & & & & & 24.8 \\
\hline 175 & 7 & BAS-2 & 0.1 & & & & & 0.30 \\
\hline 200 & 7 & BAS-2 & 0.4 & & & & & 1.20 \\
\hline 25 & 4 & LAS & 7.5 & 9.45 & 0.086 & 6.60 & 0.015 & 5.6 \\
\hline 90 & 4 & LAS & 4.0 & 9.45 & 0.086 & 6.60 & 0.095 & 3.0 \\
\hline 120 & 4 & LAS & 2.1 & 9.45 & 0.086 & 6.50 & 0.013 & 1.6 \\
\hline 150 & 4 & LAS & 0.2 & 9.45 & 0.086 & 6.22 & 0.128 & 0.15 \\
\hline 25 & 4 & BGS & $<0.1$ & 4.85 & -0.159 & \multirow{6}{*}{ 末 } & \multirow{6}{*}{ 测 } & $<0.1$ \\
\hline 90 & 4 & BGS & $<0.1$ & 4.85 & -0.159 & & & $<0.1$ \\
\hline 125 & 4 & BGS & $<0.1$ & 4.85 & -0.159 & & & $<0.1$ \\
\hline 150 & 4 & BGS & $<0.1$ & 4.85 & -0.159 & & & $<0.1$ \\
\hline 175 & 4 & BGS & $<0.1$ & 4.85 & -0.159 & & & $<0.1$ \\
\hline 200 & 4 & BGS & $<0.1$ & 4.85 & -0.159 & & & $<0.1$ \\
\hline
\end{tabular}

a) 表中溶液成分、淋滤岩石重量及溶液量分别如下: GAS: $0.004 \mathrm{~mol} / \mathrm{L}$ 甘氨酸(氨基乙酸)， $2 \mathrm{~g}, 10 \mathrm{ml} ; \mathrm{BAS}-1: 0.004 \mathrm{~mol} / \mathrm{L}$ 丙氨酸, $2 \mathrm{~g}, 10 \mathrm{ml} ;$ BAS-2: $0.0056 \mathrm{~mol} / \mathrm{L}$ 丙氮酸, $1 \mathrm{~g}, 20 \mathrm{ml} ; \mathrm{LAS}: 0.002 \mathrm{~mol} / \mathrm{L}$ (即 0.004 当量浓度) 赖氨酸, $1 \mathrm{~g}, 10 \mathrm{ml}$; BGS: $0.004 \mathrm{~mol} / \mathrm{L}$ 半胱氨酸, $1 \mathrm{~g}, 20 \mathrm{ml}$. Cu 的淋出率为反应后溶液中 $\mathrm{Cu}$ 总量与加人岩样的 $\mathrm{Cu}$ 总量的百分比.

石粉碎至 200 目备用. $150^{\circ} \mathrm{C}$ 以下的反应在玻管中进行, $150^{\circ} \mathrm{C}$ 以上的反应在高压釜中 (带聚 四氛乙烯衬套)进行. $20 \mathrm{ml}$ 溶液及 $2 \mathrm{~g}$ 岩样放人玻管, 高压金中加人 $12 \mathrm{ml}$ 溶液及 $1.2 \mathrm{~g}$ 岩样, 玻管充人样品后熔封. 高压金的充填度约为 $80 \%$, 查有关数据, 知其 $200^{\circ} \mathrm{C}$ 时的饱和蒸气压 小于 $200 \times 10^{5} \mathrm{~Pa}$. 充填样品的容器在不同温度下放置 7 天. 反应结束后, 将溶液用离心机与

表 $20.1 \%$ 氨基乙酸水溶液对岩石中 $\mathrm{Au}$ 的淋滤作用

\begin{tabular}{|c|c|c|c|c|c|c|c|c|}
\hline $\begin{array}{l}\text { 样品 } \\
\text { 序号 }\end{array}$ & $\begin{array}{l}\text { 温度 } \\
\left({ }^{\circ} \mathrm{C}\right)\end{array}$ & $\begin{array}{l}\text { 岩石 } \\
\text { 类型 }\end{array}$ & $\begin{array}{l}\text { 溶液中 } \\
\mathrm{Au}(\mathrm{ppb})\end{array}$ & $\begin{array}{c}\text { 反应前 } \\
\mathrm{pH}\end{array}$ & $\begin{array}{c}\text { 反应前 } \\
\mathrm{Eh}(\mathrm{V})\end{array}$ & $\begin{array}{c}\text { 反应后 } \\
\mathrm{pH}\end{array}$ & $\begin{array}{r}\text { 反应后 } \\
\mathrm{Eh}(\mathrm{V})\end{array}$ & $\begin{array}{r}\text { 淋出率 } \\
(\%)\end{array}$ \\
\hline GA1 & 25 & 原生矿 & 3.9 & 7.06 & 0.20 & 7.40 & 0.11 & 0.78 \\
\hline GA2 & 90 & 原生矿 & 4.2 & 7.06 & 0.20 & 7.64 & 0.11 & 0.84 \\
\hline GA3 & 140 & 原生矿 & 2.8 & 7.06 & 0.20 & 7.00 & 0.17 & 0.56 \\
\hline GA4 & 190 & 原生矿 & 2.1 & 7.06 & 0.20 & 7.28 & 0.13 & 0.42 \\
\hline GA5 & 25 & 氧化矿 & 14.0 & 7.23 & 0.12 & 7.46 & 0.12 & 2.80 \\
\hline GA6 & 90 & 氧化矿 & 250 & 7.23 & 0.12 & 6.79 & 0.16 & 50.0 \\
\hline GA7 & 140 & 氧化矿 & 107 & 7.23 & 0.12 & 6.14 & 0.22 & 21.4 \\
\hline GA8 & 190 & 氧化矿 & 3.7 & 7.23 & 0.12 & 6.84 & 0.16 & 0.70 \\
\hline
\end{tabular}


岩样分离, 经处理后, 用原子吸收分光光度计测定其中金浓度. 此外, 考虑到在一些沉积改造 型金矿中, 矿源层中的金呈微细的胶体金被岩石矿物吸附, 本实验还模拟了含氨基酸水溶液 对氧化态金矿石中金的淋滤作用,方法是将前述含金硫化物矿石经 $600^{\circ} \mathrm{C}$ 焙烧, 使硫化物分 解, 金可能是呈极细微的自然金存在或呈胶体金被粘土等造岩矿物吸附, 将此焙烧过的矿石 作为被淋滤的岩石 (即表 2 中的氧化矿), 然后用上述相同方法进行实验. 实验中的 $\mathrm{pH} 、 \mathrm{Eh}$ 值均用 pHS-20 型精密酸度计测定. 实验结果见表 2.

\section{2 讨 论}

(1) 据实验 1 , 可知低分子的氨基酸对铜有很强的淋滤络合能力, 而其他有机酸或有机酸 盐溶液, 如水杨酸钠、乙酸、乙酸钠、腐殖酸以及含有机酸的含石油地层卤水对铜的溶解度均 低于 $1 \mathrm{ppm}^{[7]}$. 实验中将氯化铜溶液加人到岩石后, 又经过 $200^{\circ} \mathrm{C}$ 的长时间烘烤, 其中的铜已 成为氧化铜微粒,氨基乙酸、氨基丙酸等对其仍有较强地溶解络合能力. $0.056 \mathrm{~mol} / \mathrm{L}$ 的丙氨 酸常温下可使岩石中 $46.2 \%$ 的 $\mathrm{Cu}$ 进人水溶液. 氨基酸对 $\mathrm{Cu}$ 的络合能力随温度增高而急剧 下降。

(2) 氨基酸是以偶极离子的形式存在的, 其通式为 ${ }^{+} \mathrm{NH}_{3}-\stackrel{\stackrel{\mathrm{I}}{\mathrm{C}} \mathrm{C}}{\mathrm{H}}-\mathrm{COO}^{-}$, 与 $\mathrm{Cu}$ 可能的络

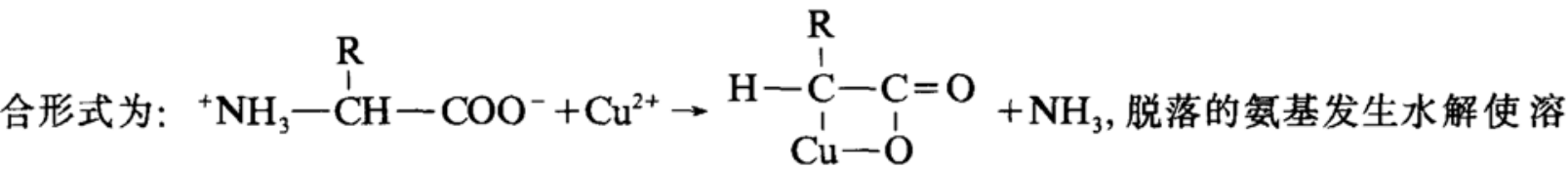
液的 $\mathrm{pH}$ 升高.据图 1 , 氨基酸对 $\mathrm{Cu}$ 的淋滤能力与氨基酸的分子量 (或碳数)呈负相关,这可能 是随着氨基酸分子量的增高,氨基与槎基之间的距离增大,氨基酸脱氨基与羰基向氨基转移 质子而产生的两个共价键之间的距离加大, 从而对金属的络合能力降低. 半脱氨酸对 $\mathrm{Cu}$ 的溶 解能力最弱, 因为半胼氨酸中的 $\mathrm{S}$ 与溶液中的 $\mathrm{Cu}$ 生成了铜蓝而发生沉淀.

(3) 据实验 2 , 可知低分子的氨基酸对氧化态岩石中的金有较强的淋滤能力. 含氨基酸 水溶液对原生硫化物矿石中金的淋滤能力不高, 主要由于岩样中自然金被封存于硫化物中, 而溶液处于缺氧的封闭环境中, 硫化物难以分解, 使得溶液中金浓度受到限制. 常温下溶液 中金浓度较低, 因为低温下氨基酸对岩石中金的溶解速率较小, 反应可能尚未达到平衡状 态, 如有足够长的时间, 低温实验的溶液中金浓度将会有所增加.

\section{参考 文 献}

[1] Disnar, J. R., Sureau, J. F., Organic Geochemistry, 1990, 16(1-3): 577-599.

[2] 刘金钟、傅家谟、卢家烂, 中国科学, B 辑, 1993, 23(9) : 993-1000.

[ 3] Giornano, T. H., Drummond, S. E., Geochimica et Cosmochimica Acta, 1991, 55(3): 2401-2415.

[4] Bowell, R. J., Gize, A. P., Forster, R. P., Geochimica et Cosmochimica Acta, 1993, 57(17): 4179-4190.

[5] 阎佐朋、徐芬芳、黄采玉, 地球化学, 1990, (1): 38-46.

[6] 刘金钟、范德廉，矿床地质，1990, 11(3): 233-240.

[7]刘金钟、傅家谟、卢家烂，现代地质，1992，(3): 309-316. 